\title{
THE SHIFTING FRONTIERS OF LITERARY STUDIES IN THE TWENTY-FIRST CENTURY
}

\author{
Shanthini Pillai \\ The National University of Malaysia \\ spillai@ukm.edu.my \\ Melissa Shamini Perry \\ The National University of Malaysia \\ mel@ukm.edu.my
}

\begin{abstract}
Traditionally seen as a discipline that was immersed in published narratives, with poetry, drama, short fiction, and novels as the sole determinant corpus, Literary Studies in the twenty-first century has progressed across the latitudes of narrativity, as the notion of text itself has pushed past established boundaries of words on a published page. The page in the contemporary context can be taken to mean the written text, the visual text, the moving text, and the hypertext, to name just a few. The articles in this Forum Kritika present a glimpse into the shifting frontiers in Literary Studies as it presents varied facets of contemporary literary scholarship by literary scholars. The discussions take us across a number of planes. They integrate both print and multimodal texts, demonstrate eclectic frameworks of reading that cross disciplinary boundaries, reveal the utilization of analytical tools from the hard sciences, and also project the inculcation of innovative and entrepreneurial skills in the literary classroom. Yet, the Forum is also mindful that however far away we trek beyond established frontiers, we must still ensure our contact with the core of our discipline, that of traditional forms of the printed text. For, if we dismiss them from our view, we run the risk of inadvertently devaluing the worth of literary fiction and its attendant academic scholarship. As such, the Forum also incorporates articles that engage with contemporary theater and novels and their inherent validity in reflecting the socio-political concerns of our world, emphasizing that these will never lose their currency however much the arena changes.
\end{abstract}

\section{Keywords}

eclectic frameworks; frontiers; literary scholarship; multimodality; narratives 


\section{About the Authors}

Shanthini Pillai $(\mathrm{PhD})$ is Associate Professor at the Faculty of Social Sciences and Humanities, and Associate Senior Research Fellow at the Institute of Ethnic Studies (KITA), The National University of Malaysia (UKM). Her research interests are anchored primarily in ethnic diversity, diaspora and transnationalism in literary and cultural texts with particular reference to the global South Asian diaspora. An emergent interest is the cultural consciousness of Catholic diasporic Indians and Chinese in Malaysia. She has headed a number of research projects on transnationalism and cultural identity as well as Catholic transcultural adaptability and has participated in transnational research projects on religious mobilities. She has held Research Fellowships at the University of Queensland, Australia and the Asia Research Institute, Singapore. Her most recent publications include "Modern Asian Ecclesiastical Interconnections: Catholic Tamil Nadu and its Diaspora in Malaysia" in The Australian Journal of Anthropology (2017) and "The Apostolic Vicariate of Western Siam and the Rise of Catholicism in Malaysia and Singapore" in the International Journal of Asian Christianity (with Bernardo E. Brown, 2018).

Melissa Shamini Perry (PhD Melb) is a senior lecturer at the Faculty of Social Sciences and Humanities at The National University of Malaysia. She teaches Literature in English and adopts a holistic and multimodal approach to teaching and learning. She received the Malaysian Minister of Education's Special Award in 2018 under the Transformative Learning- Alternative Assessment category for her creative and innovative approaches in teaching and learning. Her research interests are in the area of multimodality, applied literature, multiculturalism and alternative assessments for twenty-first century skills. She headed a pioneering research on Transmedia Storytelling in corporate and higher education contexts in Malaysia.

Kritika Kultura 33/34 (2019/2020): 378-387

(C) Ateneo de Manila University

<http://journals.ateneo.edu/ojs/kk/> 
Traditionally seen as a discipline that was immersed in published narratives, with poetry, drama, short fiction, and novels as the sole determinant corpus, Literary Studies has progressed across shifting frontiers, not only in terms of the form of the text but also in terms of the method of inquiry. We have travelled far beyond the boundaries of the text as sanctioned by I.A. Richards and the School of New Criticism that was to follow. The page in the contemporary context can now be taken to mean the written text, the visual text, the moving text and the hypertext, to name just a few. Methodological inquiry has progressed beyond pure textual analysis as well and journeyed into analytical environments that integrate numerous frameworks, not only from the social sciences and humanities but also across transdisciplinary boundaries, such as film and media, digital technology, marketing and advertising, geophysics, and even the medical sciences. These reflect the shifting grounds of twenty-first century literary scholarship as it emerges from rapidly transforming societies.

The discipline has traveled far by expanding its reach into "vigorous investments in cultural critique" (Spivak 53) and an enduring capacity to integrate multiple perspectives across time and space. These critical engagements have ranged from interweaving the linguistic and the literary with cultural and historical contexts, establishing intercultural connections, mobilizing cross-fertilization across the boundaries of disciplines, establishing ideological forces and power relations and even the "environmental humanities" (Huggan and Tiffin viii). The last is especially significant given climate change and accelerated levels of development across the globe that literally do shift the grounds that we stand on. Methods of analysis also have become increasingly innovative, from the initial integration of quantitative modes of analysis (Moretti) to the advent of the digital humanities with mediations and codings facilitated by computational devices (Berry) and even active collaborations with partners from the Science, Technology, Engineering, and Mathematics (STEM) disciplines (Liu).

The overarching attitude that drives the fiction in this special section is the acceptance of the diverse modalities, genres and disciplines in literary analysis. The articles in this issue, when viewed collectively, present the varied facets of contemporary literary scholarship as they integrate both print and multimodal texts, demonstrate eclectic frameworks of reading that cross disciplinary boundaries, reveal the utilization of analytical tools from the hard sciences, and also project the inculcation of innovative and entrepreneurial skills in the literature classroom. The inclusion of film and television texts expands the boundaries of literary genres and the applications of new methods and technologies such as multimodality and eye tracking in literature pedagogy and assessments demonstrate how literary studies embraces 21st century literacies and technology. Applications of theories and ideas across disciplines such as ecology and anthropology also expand and 
develop literary studies from an interdisciplinary perspective. However, as much as genres of aesthetic production and modes of investigation have transformed literary scholarship, certain things do remain the same. Every society, in every age, has its community of writers, be it of poetry, drama, or fiction, whose works are inevitably reflections and interpretations of the world we live in (White 149) and who continue to be "our storehouse of recorded values" (Richards 28) and as such this Forum Kritika also maintains the contemporary currency of the traditional genres of literary production and their validity in reflecting the socio-political concerns of our world. In that aspect the literary works in this issue explore historical and contemporary themes and issues in diverse cultural settings such as Malaysia, Sri Lanka, Polynesia and Sudan and provide insights and recognition to literary works and practices from these cultures and contexts.

In an age where machines and technology appear to be an essential part of human lives, it would not be an anomaly for such technologies to have some form of impact on the world of literary scholarship. Scholars have written about the changing nature of texts after the advent of the World Wide Web, from text to digital form and the use of computerized tools to resurrect texts from across ancient divides in renewed aesthetic form (McGann xiii). Yet, with the changing nature of technological advances and the Internet of Things, what began as initial efforts focused on excavating and availing archival textual material for the literary world has itself taken on new forms. The deployment of digital and multimedia technology has transformed the preferences in consuming fact and fiction. Visuals and Audio modes are now integral in the way we construct and receive narratives paving the way forward for digital and transmedia storytelling trends. Digital media through which stories are increasingly produced and consumed provide the necessary tools to create these multimodal storytelling experiences which affect readers, learners, teachers and scholars of literature. Conflict arises when developments and trends in storytelling production and consumption are not recognized especially in pedagogical and assessment practices in educational settings. Failure to recognize and include new modes of literary works and technology could lead to a decline in scholarly interest and development of literary studies. Subsequently, this would limit the contribution of the field in twenty-first-century contexts.

Therefore, in keeping with technological advancements of the times, practitioners and scholars have now integrated technology with literary studies into what can be termed as a new form of literary analytics. The article "Graphic Novels: Understanding How Fifth Graders Read Literary Text through Eye Movements Analysis" by Suriani Mohd Yusof, Zalina Mohd Lazim, Khazriyati Salehuddin, and Mizhanim Mohamad Shahimin epitomizes this new approach. It offers us a glimpse into the transformations of traditional platform of reader response and reveals ways in which one can expand its range of analytical frameworks through 
innovative modes of analyzing the scope and variety of reader reactions. The article is innovative in that it shows us how one is able to further investigations of rapid evolvements in literary skills by focusing on the performative nature of reading itself. While traditional methods would normally center on personal observations through reading journals, interviews, and focus group discussion, here the authors show us how information technology (IT) can be used in innovative means to shift the frontier of investigating patterns of reading behavior. They show that technology can be used to investigate reader responses to the verbal (language) and visual (images) elements as well as to establish patterns of visual behavior that can determine reading literacy levels in schoolchildren. Their discussion reveals a new insight into the integration of technology in literary studies, as it leads us to take a few steps away from the now already common technological world of the internet and digital media into what is a merger of the scientific and the literary, and introduces us to Tobii $\mathrm{TX}_{3} 00$ eye tracking machine, a machine that tracks the reading process. Because the machine was able to capture minute details of reading processes, it consequently led them to determine the factors that enabled and inhibited reading literacy levels. This was achieved through the reports that were produced on reader eye movement behaviors of their research subjects. As such, the paper successfully shows how the integration of technology in literary scholarship is not limited to the types of texts that are produced through digital means and the digital archiving of literary material but that innovative tools such as the one used in their research are useful and could lead to the integration and perhaps to the eventual development of other mechanisms that can help make an impact on society. This leads us to consider the question of the validity of literary studies, especially in the light of the crisis of the humanities. For, as Terry Eagleton puts it, the best way to defend the humanities is to emphasize "their vital role in the whole business of academic learning, rather than protesting that, like some poor relation, they don't cost much to be housed."

Notions of validity and marketability are such integral issues of the modern-day graduate and these are addressed at length in the article "Literature for the Twentyfirst Century: Developing Multimodality and Entrepreneurial Skills through Literature-based Assessments" by Melissa Shamini Perry. She argues how it is imperative that we dismantle the fossilized notion of literature programs as elitist and nonpragmatic or merely useful to develop good listening, speaking, reading, and writing skills. Using the sample of a study that she conducted on alternative assessments for an undergraduate literature course, Perry shows how literary studies enables the development of multimodal literacy and entrepreneurial skills which are hardly ever associated with the discipline. As she rightly points out, digital natives abound in the twenty-first-century learning environment and as such, literature classes need to emerge out of the twentieth-century cocoon and engage more with current multimodal digital literary forms, while still 
maintaining its central core of the written word. This, she argues, would heighten the appeal among students and parents alike as it would reflect the capacity of literary studies to inculcate employable skills beyond the traditional boundary of language and communications. In her discussion, she outlines the ways in which students of a Critical Appreciation course, one of the most fundamental courses of a Literature program, were guided via an innovative assessment scheme that entailed the development of a literary merchandise design to test traditional literary competencies as well as multimodal literacies and entrepreneurial skills. The aim of the assessment was to lead them beyond the traditional frontier of the essay or quiz and onwards to the production of a literary merchandise that demonstrated their understanding of a play in an alternative mode. The assessment integrated both traditional elements of Literary Critical appreciation as well as more innovative means through digitized technology. It also included a merchandise pitch where students had to promote their designs to their peers as well as the course convenor. Other elements of the product included marketing strategies in terms of justifying creative visuals and determining a target audience. These elements effectively broaden the horizon of the literary classroom and reflect a shift in teaching and learning platforms as they are propelled onwards to meet twenty-first century industry needs, issues that are often not considered as part of a literary education.

The notion of fiction too has morphed into many forms in the twenty-first century. In their article "Pursuing Imperfection: Forgiveness and Repentance in Popular Twenty-first Century Malay Television Fiction," Mohd Muzhafar Idrus, Raihanah M. M. and Ruzy Suliza Hashim choose to highlight how traditional issues such as forgiveness and repentance are repackaged through audiovisual form via the modern television series. Using the conceptual framework of democratic habits of mind which they define as the participation in discourse dimensions within human to human social settings, they journey out of the traditional platform of personal observation and move into quantitative analytical frameworks through assessing audience responses to TV fiction, in an attempt to address what they see as the changing and demanding landscape of twenty-first century settings. Methods of data collection that they highlight in their article reveal a leap into the social participatory realm as participants in their research project were obtained through calls for volunteers via public notice boards, emails, electronic mailing list software or listserv, as well as local council halls and community colleges. While the thematic issue of repentance and forgiveness is a rather common philosophical preoccupation of literary studies, the manner in which the authors chose to gain perspectives into this issue as well as the form of the text itself reveals shifting preoccupations with research methods. They also expand upon the traditional notion of stories to draw in audience accounts as formations of competing stories 
of fear and uncertainty especially over fundamental theological preoccupations of sin and repentance. In this way, the authors cleave a space for alternative stories to make their way into the literary dimension, through interweaving everyday experiences and understandings of human vulnerability and resilience, within the context of specific communities, in this context a Malay Muslim community.

Such fundamental thematic preoccupations of vulnerability and communal experience are also the focus of the next article in this Forum, "Accented Spatial Representations in the Internal Exilic Eelam-Tamil Film Viduthalai Moochu" by Ramesh Loganathan, Shanthini Pillai, and Pramela Krish, though here it delves into the marginalized voices of displaced Sri Lankan Tamils. The authors choose to look at an independent film produced by two filmmakers from the Eelam-Tamil community of Sri Lanka, who rose to fame via the alternative space of online creative production, as opposed to mainstream print or media. Relying totally on Youtube as their point of dissemination, the two filmmakers were able to provide insight into the Eelam-Tamil experience that more often than not lies on the cusp of the global imaginary. As such, the film is posited as playing the same role as literary fiction, creating an alternative artistic narrative of the thematics of exilic Eelam-Tamil experience. These, the authors argue, are encapsulated in markers of ostracization, subjugation, oppression, marginalization, and confinement pertaining to loss and trauma of the civil war in Sri Lanka and subsequent alienation in their escape to the hinterland, juxtaposed between images of fertility and mortality, movement and stasis. The article then, if viewed from a literary angle, can be seen as expanding the breadth of analytical frameworks of setting and tone to cinematic scale, while duly emphasizing elements of space and time, which are integral to the employment of the device in fiction. The article subsequently outlines the ways in which the cinematic aesthetics of spatial and the temporal representations of the Eelam-Tamil homeland render forth the complexities of displacement and deterritorialization of the Eelam-Tamil community. In addition, it also highlights the multitude of the trajectories of exilic experience vis-a-vis journeys, multilinguality, and accented speech, all of which are fundamental elements of print fiction too. An added feature, given that film renders more than what fiction is able to, is asynchronous sound which the authors argue are crucial in accentuating the fractured and fracturing experiences of fear and horror of the Sri Lankan civil war for the Eelam-Tamils. These in turn, as the discussion shows, are able to bring forth politically suppressed voices such as the two Eelam-Tamil filmmakers from the shadows as they evade the cogwheels of interrogation, censorship, imprisonment, and even death sentences from overtly oppressive local regimes. In this way, the article shows the ways in which literary scholarship, through such ventures into the terrain of filmic production can successfully augment sensory perceptions of creative narratives in 
multimodal form. We are led to witness the integration of sonic scapes of spoken lingo, asynchronous sound and muted voices coupled with moving images that present journeys and both physical and mental border crossings. Yet, as much as it pushes the boundaries of thematic exploration, the article also observes the fundamentals of literary analysis, with its focus on the persuasive compositional techniques of representation in terms of electronic and textual epistolarity, the employment of self-reflexivity, and self-inscription. All of these serve to emphasize the magnitude of political strife and severely fractured social experience of the internally exilic Eelam-Tamil in Sri Lanka.

Yet, however far away we trek beyond established frontiers, we must still ensure our contact with the core of our discipline, that of traditional forms of the printed text. For if we dismiss them from our view, we run the risk of inadvertently devaluing the worth of literary fiction and its attendant academic scholarship. The three remaining articles in this special forum engage with contemporary theater and novels, emphasizing that these will never lose their currency however much the arena changes. Theater has always played a significant role as a vehicle for dramatizing the disquietudes of sociopolitical friction. We have witnessed this most notably in Elizabethan plays, with its reflection of the various crises of political legitimacy and murderous strains of uninhibited ambition, all common preoccupations of Shakespeare, Marlow, and Jonson. We have seen such thematics take on new forms as theater changed over the centuries, most notably in the twentieth century, with existentialist preoccupations that brought about the Theater of the Absurd and, with it, total theatrical distortion of reality, as evinced in the plays of Camus, Beckett, and Pinter. Such forms of resistance have had tremendous influence across both time and space, and the article "Dramatizing History: Reading Bakhtin's Carnival in Kee Thuan Chye's Plays" by Erda Wati Bakar, Noraini Md Yusof, and Ravichandran Vengadasamy reflects this very impact in an Asian context, by focusing on the utilization of Malaysian theater as political expression and resistance. Employing established frameworks of New Historicism and Bakhtin, they explore two plays of a Malaysian dramatist renowned for his political satire and show how the dramatic content reconstructs key issues in Malaysian politics through carnivalesque means. These, they argue, effectively dismantle historical truths as they are able to subvert established narratives of power and privilege through temporary suspension of hierarchical rank, ambivalent laughter as mockery, and acts of overt defiance of authority and hierarchy through self-fashioning agency. As such, if what is established as historical truth is merely one narrative position, then, as the authors argue, there will always be a host of alternative stories to be reviewed and it is necessary to critically reflect on the very nature of historical truth. Narratives of the past will always have currency in the present and, in similar vein, traditional frameworks such as New Historicism and 
the Carnivalesque will never lose their potency in literary scholarship, and neither will the form of the theater.

Alternate hierarchies and subversion of power are also the subject of the next article, as we move from the body politic to mother earth and specters of the otherworldly. In "Monsters at the End of Time: Alternate Hierarchies and Ecological Disasters in Alaya Dawn Johnson's Spirit Binders novels," Anita Harris Satkunananthan explores the role that creative fiction plays in presenting the magnitude of the impact of ecological disasters through the use of supernatural tropes such as the vampire, spirits and other such intermediaries. She argues that such tropes that hover between the liminalities of the realm between life and death are useful in presenting the clash between the forces of a severely impaired natural world reeling from environmental disaster and the ruptured factions of humankind. The latter, equally affected by a world turned on its head, are consequently hurled into states of liminalities between life and death that bring with it a set of alternate hierarchies. The discussion utilizes traditional frameworks of in depth character analysis such as thoughts, feelings, and motivations, that are crucial in augmenting the impact of ecological disaster that subsequently lead to personal choices that border on the monstrous and that ultimately lead to deeply conflicted psyche. However, it also introduces a new term, that of the Postcolonial ecoGothic, which she argues is fundamental to interrogate the power relations of domination and resistance that abound in the selected novels. As such the article reveals that new analytical trajectories are still possible, through navigations and border crossings within the realm of Literary Studies, which can in turn lead to new ecologies of reading, even as the fundamentals of characterization, with its own trajectories of the cause and effects of personal choice, remain the same.

Personal choice is also the subject of the article "Re-defining Home and Belonging in Leila Aboulela's The Translator" by Amrah Abdul Majid as it interrogates the issues of the performativity of religious piety, spiritual doctrine, and the dialectics of the gendered Muslim self within diasporic contexts and attendant cross cultural issues. The article focuses on translation as a trope in its discussion of the dialogics that ensue when two characters with entirely oppositional spiritual convictions engage in a romantic relationship. It proceeds to do this by reading the religious practices of the protagonist as a text that transcribes piety of the self. It specifically highlights the paradox of orthodox observance of spiritual doctrines that result merely in repetitive empty rituals rather than a transcendent understanding. It subsequently subverts the usual reading of the discordant dialectics between Muslim and non-Muslim understanding of Islam that are often seen as untranslatable and as such insurmountable. This is relayed through the utilization of fundamental 
aspects of characterization and a discussion of the transformative processes that both characters undergo as they arrive at a better understanding of themselves and Islamic religiosity through deeper interpretive engagements with piety and spirituality, as opposed to repetitive ritual and erudite neutrality.

\section{CONCLUSION}

The articles in this Forum Kritika are but a window into a rapidly changing literary universe that is evolving from being archaic, elite, and puritanical to becoming dynamic, multidisciplinary, and cross-cultural in its bid secure its place in the twenty-first century. Literature departments all over the world are constantly driven to prove their validity in a world that appears to be spinning rapidly toward digital revolutions that leave the humanities in the wake of a crisis that appears to have no end in sight. Those who choose to stay and fight the good fight know that they have no alternative but to move with the times. As seen in the diverse perspectives presented above, literature scholars and educators are embracing the challenge to continuously develop the field by engaging with current interests, needs, and technology. Yet, however far the journey takes us, the core of literary studies, humanity, is constant and timeless. The discussions that are presented here may reveal the shifting grounds of literary scholarship and the eclectics of texts and textuality, yet the depth of human emotions, intricacies of language, literary aesthetics, and close analysis remain an ever present part of the mode of investigation of literary scholars. For in the end, in the words of T.S. Eliot "We shall not cease from exploration / And the end of all our exploring / Will be to arrive where we started / And know the place for the first time." 


\section{Works Cited}

Berry, David M., editor. Understanding Digital Humanities. Palgrave Macmillan, 2012.

Eagleton, Terry. "The Death of Universities." The Guardian, 17 Dec. 2010, https://www. theguardian.com/commentisfree/2010/dec/17/death-universities-malaise-tuition-fees. Accessed 1 Nov. 2018.

Eliot, Thomas Stearns. Little Gidding. Faber and Faber, 1942.

Kritzer, Amelia Howe. Political Theatre in Post-Thatcher Britain: New Writing 1995-2005. Palgrave Macmillan, 2008.

Huggan, Graham, and Helen Tiffin. Postcolonial Ecocriticism: Literature, Animals, Environment. Routledge, 2015.

Liu, Alan. "Where Is Cultural Criticism in the Digital Humanities?" Debates in the Digital Humanities, edited by Matthew K. Gold, U of Minnesota P, 2012, pp. 490-509.

McGann, Jerome. Radiant Textuality: Literary Studies after the World Wide Web. Springer, 2016.

Moretti, Franco. Graphs, Maps, Trees: Abstract Models for a Literary History. Verso, 2005.

Richards, Ivor Armstrong. Principles of Literary Criticism. Routledge, 2001.

Spivak, Gayatri Chakravorty. Outside in the Teaching Machine. Routledge, 2012.

White, Elwyn Brooks. "The Art of Fiction." The Paris Review Interviews IV, edited by Phillip Gourevitch, Picador, 2009, pp. 128-151. 